\title{
La ética de la liberación ante la ética del discurso
}

\author{
ENRIQUE DUSSEL \\ UAM. México
}

En este artículo el autor responde a cuatro objeciones que Karl-Otto Apel desarrolla en el trabajo: «La ética del Discurso ante el desafío de la Filosofia de la Liberación" (Isegoría 11, pp. 108-125). 1) La miseria, que es una evidencia de exigencia ética, necesita para alcanzar validez intersubjetiva de la mediación hermenéutica de las ciencias sociales críticas. 2) En el nivel ideológico la Filosofía de la Liberación no acepta ser criticada de historicismo y de un cierto economicismo marxista standard, ya que reconstruye el pensamiento de Marx de manera original. 3) La trascendentalidad trans-ontológica que propone la Filosofía de la Liberación es propia de la alteridad de tipo levinasiano. 4) Aunque se acepta la necesidad de efectuar una fundamentación formal antiescéptica, lo que importa ética y materialmente es la demostración ante el cínico que pretende justificar la muerte de la verdad ética de la praxis de liberación.

Tanto en Moscú ${ }^{1}$ como en São Leopoldo (Porto Alegre, Brasil) ${ }^{2}$ K.-O. Apel se refirió al tema «La Ética del Discurso ante el desafío de la Filosofía de la Liberación latinoamericana» - segunda parte ${ }^{3}$.

Una respuesta integral al artículo de Apel, que contiene tan variado número de cuestiones, que se sitúan igualmente en muy diferentes niveles, merecería un trabajo de mucha mayor extensión que el presente ${ }^{4}$. Tocaré solamente cuatro puntos ${ }^{5}$.

' En el XIX Congreso Mundial de Filosofia, llevado a cabo en agosto de 1993.

${ }^{2}$ En el IV Seminario Internacional sobre el díalogo entre la Ética del Discurso y la Filosofia de la Liberación latinoamericana, llevado a cabo del 27 de septiembre al 1 de octubre de 1993 (Fonet-B., 1994).

'Ape1, 1995.

${ }^{4}$ Debo confesar que he comenzado una obra de largo aliento, que consistirá en una nueva versión de la ética que escribí entre 1970 y 1975 (Para una ética de la liberación latinoamericana, en cinco tomos, Siglos XXI, Buenos Aires, t. I-II, 1973; t. III, Edicol, México, 1977; t. IV-V, USTA, Bogotá, 1979-1980), y que denominaré Ética de la Liberación, donde trataré arquitectónicamente las cuestiones planteadas por Apel $\rightarrow$ y muchas otras, evidentemente.

"Sobre los otros estadios de la discusión con Apel véanse mis articulos: Dussel, 1990a; 1991; 1992a; 1993a; 1994a; 1994b. Debe considerarse, además, que mis lecciones en Frankfurt (Dussel, 1993 b) contienen muchas respuestas a preguntas criticas formuladas por Apel en el seminario de México de 1991 (Fornet-B., 1992). Mi obra Dussel, 1996, reủne mis materiales del debate (tanto en castellano como en inglés). 


\section{Algunas reflexiones sobre el punto de partida}

Una objeción de Apel en el artículo al que me estoy refiriendo ${ }^{6}$ consiste en que, aunque reconoce que la pobreza, la miseria de las grandes masas del mundo del capitalismo periférico (el factum), debe ser considerada como una «experiencia auténtica» ${ }^{7} \mathrm{y}$, por ello, una evidencia de exigencia ética, sin embargo, en cuanto esa evidencia siempre está mediada por una interpretación científico-empirico social, se torna ambigua, y con ella toda pretensión a la hora de una «praxis de liberación» o de la formulación de una teoría a ella asociada. En dicha mediación interpretativa se corre siempre el riesgo de «dogmatismo»; pero, más fundamentalmente, la filosofía de la liberación no puede derivar de esta evidencia indubitable de su punto de partida, simultáneamente empírico y ético, automáticamente un primado de la evidencia concreta y de la validez intersubjetiva para su elaboración teórica y su puesta en obra práctica —objeta Apel ${ }^{8}$ -

Acto seguido Apel muestra la ventaja de la Ética del Discurso, ya que parte de una fundamentación trascendental intersubjetivamente válida - cuestión que trata en Apel, 1995, $\$ 2.2-$, no advirtiendo que su dificultad estriba en el momento previo a la misma fundamentación trascendental y, en mayor medida, en los problemas previos a la aplicación en el momento histórico-empírico de la Parte B (Apel, 1990, \&2).

En efecto, antes de poder emprender el proceso reflexivo que partiendo de la facticidad alcanza el nivel pragmático-trascendental de la Parte $\mathrm{A}$, y, por supuesto, antes de poder «aplicar» los principios éticos en el nivel empírico-histórico de la Parte B de la fundamentación, el sujeto reflexivo debe ya presuponer siempre a priori $\longrightarrow$ a priori con respecto al proceso de trascendentalización, y a posterion de la facticidad misma del estar-ya-en-un-mundo donde se argumenta (o se trabaja, se ama, etc.) - que el Otro ha sido «reconocido" ${ }^{9}$ como persona. Es decir, si alguien se encuentra ante una piedra, una mesa o ante el esclavo de Aristóteles, no tiene por qué argumentar, ni efectuar un producto para intercambiarlo con «el Otro», porque no «hay» ningún Otro; hay sólo «cosas» (con las que no se argumenta: o se las conoce o se las usa desde una asimetría, desde el «poder»).

Para Aristóteles, por ejemplo, la amistad (philia) es «amor de lo semejante por lo semejante» ${ }^{10}$; hay una cierta «semejanza (omoióteta)» ${ }^{11} 0$ «igualdad

"Que repitc en parte lo ya indicado en Apel, pp. 18 y ss.

Apel, 1995, $\$ 110-111$.

Ibid.

- Véase Honneth, 1992. Sin embargo, Honneth sólo sitúa el problema del «reconocimiento (Anerkennung)" con respecto al «nosotros» o a la comunidad de comunicación. No plantea el problema del $\times$ re-conocimiento del Otro, de la Alteridad (Alterität) del excluido en la exterioridad (Exterionität) o del dominado en el sistema de opresión. Es restrictivo y se le escapa, nada menos, que el re-conocimiento propiamente ético del Otro como otro.

12 Aristóteles, Ética a Nicómaco, VIII, 1, 1155b, 8.

"Ibid., 1155 a 34. 
(isóteti)» ${ }^{12}$. Por ello no se argumenta ante el esclavo, porque no se encuentra en «semejanza»; diríamos hoy: no se encuentran en la comunidad de comunicación real, donde se reconocen los participantes como iguales. Alguien puede argüir que el esclavo se encuentra potencialmente como participante en cuanto afectado por un acuerdo posible acerca de sus intereses. Pero el problema se sitúa, fácticamente, en que «re-conocer» a alguien en la asimetría como persona, igual, y como Otro, es ya la «experiencia ética» (el factum) que lo descubre como dominado o excluido desde su previo conocimiento como persona. Es decir, la norma ética básica (el argumentar presupone el participar en una comunidad de personas tenidas por iguales) se desarrolla desde el a priori del re-conocimiento del Otro. La norma básica se deduce del "re-conocimiento" del Otro como persona; dicho re-conocimiento es pre-científico y pre-reflexivo (anterior a la fundamentación y a la misma argumentación aún como posible). Éste es el tema que ya hemos planteado en la ponencia de Sâo Leopoldo ${ }^{13}$. Es toda la cuestión de la «razón pre-originaria» en Levinas ${ }^{14}$.

En el momento ilocucionario del «acto-de-habla», cuando "Yo-te expreso que $p$ ", ese establecer el «encuentro» (el "cara-a-cara» de Levinas ${ }^{15}$ ) o la "relación práctica» con el Otro como persona (en el: «Yo- >te...»), como otro, es la condición previa absoluta para que dicho «acto» sea un acto «comunicativo".

Por todo ello, y si partimos de una posición de asimetría, el «re-conocimiento» del esclavo ${ }^{16}$ como persona, supone: $a$ ) un «conocimiento» del esclavo como función o cosa (funcional fácticamente en el sistema); b) un «conocimiento» del esclavo como persona (acto segundo y ya ético ${ }^{17}$.); c) un pusterior "re-conocimiento" (acto reflejo en tercer término ${ }^{18}$ ) por el que, como en un retorno, se confronta desde la persona a dicho ser humano ahora como esclavo (dentro de un sistema de dominación) situado y juzgado éticamente como negado: como esclavo dominado, explotado.

El mero «conocer» al esclavo como función o cosa (a la mujer en el patriarcalismo como excluida o «inferior», al «negro» en la sociedad de raza blanca,

1.. Ibid, VIII, 6, $1158 \mathrm{~b}, 1$.

13 Dussel, 1994b, § 2.3: «Afírmación analéctica: Asi me nació la conciencia: la razón ética originaria» (pp. 156 y ss.).

"Levinas, 1974, p. 212. Véanse Sidekum, 1993, pp. 51 y ss.; Schelkshorn, 1992, pp. 74 y ss.

${ }^{15}$ Este tema lo hemos situado en Dussel, 1991, § 1.1. Véase Theunissen, 1965; véase igualmente el tema en Pedro Laín Entralgo (Laín Entralgo, 1961).

${ }_{16}^{16}$ Para Aristóteles no se puede establecer «amistad» con el «inferior», con el Otro como otro: «En cuanto al esclavo (doûlos) no puede haber amistad en él» (ibid., VIII, 11, 1161b, 4), porque no se degrada (no hay experiencia de lo que pudiera ser algo así como «compasión», «solidaridad» 0 «misericordia»).

${ }^{17}$ Aristóteles toca la cuestión al decir que el esclavo "como humanon (ibid.) puede ser objeto de amistad, "porque cierta justicia parece existir con respecto a todo humano en todas las relaciones en que éste pueda entrar por léy o por contraton (ibid).

${ }^{1 \approx} \mathrm{El}$ «re- $\left.(a n-)\right\rangle$ del «Te-conocimiento (An-erkennung) $)$ indica ese volverse sobre sí, reflejarse, reflexionarse. 
etc.) es de alguna manera «ofrecer en sacrificio a las personas, los instrumentos, para mantener en pie la cosa» ${ }^{19}$. Es decir, es conocerla como «parte funcional» de un sistema (esclavista) - como al obrero asalariado se lo conoce en el sistema del capital ${ }^{20}$ - El momento ético por excelencia, kath'exokhén, consiste cn el «conocer práctico» que perfora la mera funcionalidad instrumental (el instrumento de Marx) y constituye al Otro como persona ${ }^{21}$, como Otro que el sistema (en el sentido de Niklas Luhmann) como totalidad (Levinas). Esta racionalidad ${ }^{22}$ ético-originaria es anterior a toda argumentación, y por lo tanto anterior al proceso de trascendentalización y de fundamentación apeliana:

«Una razón anterior al comienzo, anterior al presente, pues mi responsabilidad por el otro se impone antes que toda decisión, antes que toda deliberación" [antes que todo argumento] ${ }^{23}$.

$\mathrm{Si}$ se argumenta es «porque el Otro es persona» - y no a la inversa-. Es decir, el factum empírico del que he hablado, y que Apel acepta como una cvidencia de exigencia ética, para ser ético, exige una re-flexión: desde el Otro ya reconocido como persona se descubre a la esclavitud como perversidad, como negatividad. Ese factum manifiesta a la «función» en el «sistema» (totalidad), a la persona del Otro como «parte-negada» o como sujeto no-autónomo (ya que la única estructura autoreferente y autopoiética es el mismo sistema como totalidad), como interpelante, y, por ello, el mismo sujeto del reconocimiento se sitúa ahora como co-responsable ${ }^{24}$ de la negación del Otro (solidaridad ante la miseria, compasión ${ }^{25}$ ). Todo esto constituye el «acto-del-re-conocimiento-del-Otro" (que va más allá del análisis de Honneth).

Sólo en un scgundo momento, cuando se pregunta problematizada o críticamente, en vista de la validez intersubjetiva, por la causa, la estructura, el sistema, etc., que está a la base de la negación ética del Otro, y se intenta

"Marx, 1842, p. 4. Véase Dussel, $1993 \mathrm{c}$.

20 «Sistema» aquí aún en el sentido de Niklas Luhmann: «Nuestra tesis de que existen sistemas puede ahora delimitarse con más precisión: existen sistemas autorreferenciales" (Luhmann, 1984, p. 31). El individuo en un sistema tal actúa como ufunción».

${ }^{2}$ En Sâo Leopoldo, Hans J. Sandkühler me pidió que explicara esta constitución del Otro como persona. La respuesta la expondré, en parte, en el cap. 4.2 de la Ética de la Liberación en elaboración.

22 Será objeto del cap. 5.7 de la nombrada Éica de la Liberación, al estudiar los «tipos de racionalidads.

${ }^{33}$ Levinas, 1974 , p. 212.

${ }_{24}$ Esta es la «re-sponsabilidads (del latín: spondere: «tomar-a-cargo-al-Otros indefenso) a priori anterior a la responsabilidad de Hans Jonas o Apel.

${ }^{25}$ Reyes Mate, 1991: «Por una ética compasiva» (pp. 141 y ss.), sitúa correctamente la cuestión, desde Horkheimer (véase Schnädelbach, 1986), citando: «Ese amor no se puede entender sin la orientación a una vida futura feliz del hombre, orientación que no viene por revelación sino que brota de la miseria del presente» (Horkheimer, «Materialismus und Morals, p. 94; cit., R. Mate, 1991, p. 143). Sin embargo, Horkheimer opina que la compasión es un usentimiento moral»; pienso, en cambio, que es un momento primero de la «razón ética originaria», y la diferencia es esencial, ya que no afirmamos un ambiguo esentimentalismo» compasivo. 
alcanzar una «explicación (Erklärung)», entonces, sólo entonccs, sc rccurre a la mediación interpretativo-científica, que no es neutra ni inocente. Aquí la Ética de la Libcración tiene un criterio para la crítica, para alcanzar validez intersubjetiva, para la elección de los instrumentos de interpretación científica, y aun para participar en esta o aquella comunidad de comunicación (¿la dominante o la dominada o excluida?, etc.), del que carece la filosofía que toma el mundo dado meramente (el capitalismo en el presente, p. ej.) como único punto de partida (y tal es el caso de la Ética del Discurso, tanto en el proceso de reflexionarse hacia lo trascendental como cuando intenta aplicar la norma ética meramente formal o procesual).

El factum no se da en una inmediatez primera evidente empírico-positiva (esto sería un positivismo ético ingenuo o dogmático), porque dicho factum se lo constituye desde un mundo presupuesto (en sentido heidcggeriano), y, 'emás, se lo aelabora» éticamente desarrollándolo como «re-conocimiento»

I Otro, dando ya un sentido y un juicio a su negación (dominación o exclusión) como perversidad. Pero, además, de dicho factum no se deriva tampoco «automáticamente [...] la validez intersubjetiva para su claboración teórica y su puesta en obra práctica». Y csto porque dicha validez es fruto también del uso de la mediación científica y de un proceso comunitario argumentativo. Sin embargo, esa validez intersubjetiva, para ser critica, debe mediarse por cl uso de ciencias sociales (u otras) críticas -como v. g. por el uso del «concepto do dependencia» en las relaciones Norte-Sur dentro del sistema mundial ${ }^{26}$, o el uso de Marx en la crítica actual del capitalismo.

La Ética de la Liberación puede emprender, desde el «re-conocimiento» del Otro, y desde el imperativo o norma ética básica («iLibera al Otro negado en su dignidad!» ${ }^{27}$; sea el pobre, la mujer, la clase obrera, la nación periférica, la cultura popular dominada, la raza discriminada, las generaciones futuras, etc.), el proceso (procedimental discursivo) de la validación intersubjetiva del factum, v. g. de la perversidad de la miseria de los explotados o excluidos (teniendo en cuenta que hay «comunidad de comunicación hegemónica» o «dominante», y, por ello, la validez propiamente ética puede darse al comienzo sólo entre los mismos dominados o excluidos ${ }^{28}$ ).

26 Véase la ponencia de Hinkelammert, 1995.

$n$ Todo el tema de los criterios, categorias y principios élicos se tratará exhaustivamente en la Ética de la Liberación, donde describirenos y daremos las razones del porqué de una arquitectónica diferente al de la Ética del Discurso.

${ }^{27}$ Éste es todo el tema de la «concientizaçâo" de la comunidad de los dominados ( $\mathrm{v}$. g., clase obrera) o excluidos (v.g., etnias indigenas en América Latina) indicado en Dussel, 1994b, \$\$2.1-2.3: desde la afirmación analéctica de la alteridad (del Otro como afectado, dominado o excluiơo) en la asimetria inicial (y la Ética de la liberación es una ética que como situación normal parte de la asimetria, y por ello es universal, no como la Ética del Discurso que sölo puede partir de la simetria, siendo entonces una ética particular del «Estado de derecho", que se cumple en la minoría dominante de la humanidad), por la «toma-de-conciencia» (propio «re-conocimientow comunitario) - donde la mediación específica es esencial-, hasta la interpelación a la solidaridad para efectuar un proceso efectivo o politico de liberación (o de plena participación 


\section{2. "Eurocentrismo", «historicismo» y lo «económico»}

Apel toca la cuestión ideológica ${ }^{29}$. Acepta que puede haber ideológicamente un cierto eurocentrismo, tanto en la filosofía europea, norteamericana como latinoamericana (en diversos grados). Por mi parte, no soy tan simplista como para pensar que el «eurocentrismo» de la filosofía europeo-norteamericana, y la inautenticidad eurocéntrica de la filosofia latinaomericana imitativa, se reduzca sólo a una relación de causa-efecto del capitalismo mundial, que tendría una estructura, que también puede caricaturizarse simplificadamente, con un centro y una pcriferia. El fenómeno del «eurocentrismo» es mucho más amplio; es particularmente cultural, político y también filosófico ${ }^{30}$. Por ello, una vez más, no puedo aceptar que sea mi posición una «crítica cuasi-marxista» (entiéndase, del marxismo standard que siempre he rechazado).

Entiendo por «eurocentrismo» la pretensión que identifica la «particularidad» curopea con la «universalidad» sin más. Ningún filósofo puede dejar de ser eurocéntrico hoy si no toma conciencia crítica y expresa de la cuestión misma del eurocentrismo. Advertida su existencia, sólo entonces se puede alcanzar una conciencia crítica refleja - y esto ciertamente ha acontecido en Apel.

Por mi parte, no puedo aceptar que el «eurocentrismo» sea una construcción «supra-estructural» que responda automáticamente a una «base» capitalista, porque he negado que el «esquema base-supraestructura» tenga relevancia central para Marx ${ }^{31}$. Pienso en cambio en un eurocentrismo más sutil, que he denominado la «falacia desarrollista»: el pretender que todas las culturas seguirán el camino efectuado por Europa (de que debieran, v. g., pasar de lo pre-moderno a lo moderno, del capitalismo clásico al capitalismo tardío). Lo mismo puede decirse de la pretensión de que el europeo hoy se encuentra en una situación clara y definitiva "postconvencional» -ültimo grado del desarrollo moral de Kohlberg-. Pienso que se puede afirmar que ninguna eticidad será nunca completamente postconvencional, y que toda moral universal (aun la de Apel o Habermas) siempre se articulará de hecho en torno a una eticidad convencional dada (v. g. la europeo-norteamericana, conservadora, liberal o socialdemócrata). Es ingenuo pensar que hoy el filósofo crítico europeo pueda situarse en su vida cotidiana postconvencionalmente, no advirtiendo que sus «reacciones» concretas siguen siendo las de un miembro de la cultura occidental. Ante un budista —que niega a la persona, en una pretensión de superación

en una comunidad de comunicación futura en simetria: $\$ 2.4$ ). Esto merecería una rearticulación de Teoria y praxis.

50 Véase Apel, $1995, \$ \$ 2.3$ y 2.4, pp. 113-115.

30 Véase Amin, 1989. Ya he escrito el cap. 2 de la Ética de la Liberación en claboración, donde explico el tema, dentro de una visión distinta de la historia mundial (cap. 1), y por ello mismo de la Modernidad (cap. 2.). He dicho algo en mi obra Dussel, 1993b.

"Véase Dussel, 1993c, pp. 302 y ss. 
de la individualidad para alcanzar el no-sufrimiento- la Ética del Discurso, al afirmar como personas iguales a los participantes simétricos de una comunidad de comunicación, manifestaría una visión semito-occidental del ser humano (cvidenciado en cl concepto de persona, que no existe en el budismo, y que de Boecio a Tomás o Kant campea en el pensamiento judío, cristiano o musulmán).

Tampoco el viejo Marx, al menos después de 1868 , tiene una visión hegeliano racionalista o historicista, de un proceso histórico que cumple etapas necesarias que pueden anticiparse. Ya me he referido en otra parte a este punto ${ }^{32}$. Y, por otra parte, la crítica de Popper al pretendido historicismo de Marx ha perdido todo su crédito últimamente ${ }^{33}$.

Si es verdad que Marx critica a las «morales» (serían las Sittlichkeiten hegelianas) como relativas a su tiempo (v. gla burguesa), sin embargo tiene criterios que trasciende los sistemas económicos históricos. Por ello hemos escrito que "El capital es una ética» ${ }^{34}$. Marx tiene un criterio universal de su ética: la dignidad ${ }^{35}$ del sujeto, la persona, el trabajo vivo, desde donde puede criticar al capital como el sistema donde el sujeto, el trabajo vivo, es subsumido (la Subsumtion es la categoria ética por excelencia de Marx), es alienado o negado como sujeto, como persona autónoma. El sujeto como ser orgánico vivo es el sujeto de la argumentación, de donde debe partir la pragmática, cs decir, debe partir de una económica (si se la entiende como el nivel donde se da la reproducción de la vida como condición absoluta de la misma subjetividad: los criterios materiales últimos). Es evidente que la económica supone igualmente siempre a la pragmática (como mediación consensual intersubjetiva en la gestión de lo económico) ${ }^{36}$. Lo económico indica la corporalidad del ser humano que exige éticamente ser reproducida como condición absoluta de toda otra actividad posterior. Es decir, la persona es «corporalidad (Leiblichkeit) ${ }^{37}$, ya que de lo que hablamos no es de un ángel que sólo argumenta, sino que es un ser viviente, corporal, humano. En Sâo Leopoldo expuso Franz Hinkelammert:

"Vêase Dussel, 1994a, en nota 52.

${ }^{33}$ Véase Hinkelammert, 1984, cap. 5.

* Véase Dussel, 1990 , cap. 10.4 , pp. 429 y ss.

${ }^{3}$ Habla del «sentimiento de la propia dignidad». Véase Marx, 1873, p. 209, 25; Marx, 1879, p. 367. La persona del trabajador no tiene valor (y por ello precio) porque es fuente creadora de valor.

${ }^{33}$ Véase Ulrich, 1992, donde sin embargo se sitúa en el nivel de la razón teórico económica (y no la razón propiamente económico-práctica concreta). Por ello habla de una razón o comunidad económico-pragmática, y no propiamente de una razón económica pre-pragmática (o de una «comunidad de vida» a acomunidad de productores", como se expresaba Marx, anterior a la «comunidad de comunicación»).

${ }^{37}$ Ésta es también una determinación criterial para Marx (véase Dussel, 1985, pp. 138 y ss.): «solamente una objetividad que coincide con su inmediata corporalidad" (Marx, 1857, p. 235). 
«El acceso a la realidad corporal -esto es, el estado corporal incólume en la relación social entre los seres humanos-, y el acceso a los valores de uso en la relación del ser humano con la naturaleza, es el criterio de validez ética de las normas en el caso concreto» ${ }^{38}$.

Es en el nivel de la económica originaria, en el de la existencia corporal misma humana que necesita su reproducción, que he situado a la «económica» (Oekonomik) -que no debe confundírsela con la «economía» (Wirtschaft). Participar de una «comunidad de productores» o «comunidad de vivientes» cs condición primera del sujeto argumentante como viviente ${ }^{39}$. La Ética de la Liberación, por su parte, considera como el criterio y punto de partida la corporalidad sufriente del dominado o excluido: la alteridad del Otro ncgado en su dignidad, en cuanto no puede reproducir su vida.

\section{La trascendentalidad trans-ontológica}

Apel pide aclaraciones a la Filosofía de la Liberación sobre otras cuestiones fundamentales. No se explica cómo pueda asumirse una posición «ontológica» 0 "historicista", que se inspira en Hegel, Marx o Hcidegger, y otra tal como la de una «metafísica transontológica» de un Levinas; no se comprende tampoco cómo pueda ignorarse el «futurismo» de Marx; qué pueda significar la diferencia entre lo «griego» y lo «semita»; y sobre todo cómo pueda superarse «el todo de toda posible verdad como relacionada a un logos» ${ }^{40}$. Lo anterior aparece a Apel como posicioncs contradictorias, o al menos ambiguas o confusas. Me agradan las preguntas que me lanza porque me permiten aclarar una dificultad que tienen Habermas y Apel en comprender la posición de Levinas y de la Filosofía de la Liberación. Es toda la cuestión de la «Alteridad» ${ }^{41}$.

Apel escribe en referencia «al todo» cn torno al cual se desarrolló el concepto de la dialéctica ontológica en Platón o Hegel:

«El todo del ser y de su verdad comprensible por el logos [...] El todo de todo horizonte de comprensión del ser pensable por mi, y en ese sentido la inseparabilidad dialéctica del ser (como la identidad) y el no-ser (como la diferencia) ${ }^{42}$.

3 Hinkelammert, 1994, \$ III.

3 Este tema lo hemos repetido insistentemente en el debate fvêase Dussel, 1990 , \$ 4 (ed. alemana 1); Dussel, 1991, 3; Dussel, 1992b, \$4-5; Dussel, 1993a, \&4; Dussel, 1994a, \$\$3-4].

Apel, 1995, 2.6, pp. 116 y ss.

"He analizado ciertos aspectos del asunto en trabajos anteriores [Dussel, 1990a, $\$ 4.1$ (ed. alcmana \$ 1); Dussel, \$ 1.1, 2; Dussel, 1993a, \&3; Dussel, 1994b, \$\$ 2.1-2.3]. Hoy desen diferenciar en la kalteridad del Otro dos dimensiones: como dominado en el sistema o totalidad (por Subsumtion) o como excluido - este último caso lo denominaremos ahora, para cyitar malentendidos: axterioridad $\%$.

*. Ibid. 
De otra manera Parménides lo expresó antes que Platón: «... to gàr autò noeîn estin te kaì eînai» ${ }^{43}$. El «ser» (como «comprensión del ser» ${ }^{44}$ ) puede coincidir con cl lógos (Platón), con el verstehen (Heidegger), que es lo «pensable» (denkbar). Ya en nuestra obra Método para una Filosofía de la Liberación ${ }^{45}$, hemos mostrado la imposibilidad de la coincidencia, inmediatez o identidad entre el scr, la "verdad del ser» con la realidad ${ }^{46}$. A partir del Sartre de la Critique de la raison dialectique, del Zubiri de Sobre la esencia, y fundamentalmente de Levinas, ampliamos esta no-identidad entre el «mundo» (la «comprensión del ser», la totalidad del sentido, el ser) con la realidad ${ }^{47}$ de las cosas físicas, pero mucho más con la realidad de la res eventualis que es el Otro como sujeto ético. Con Sartre comenzamos a abrirnos a la problemática desde una ontología de las ciencias sociales. Pero fue Levinas el que situo, para nuestro grupo de filósofos latinoamericanos a finales de los años sesenta, la problemática de la realidad (Realität), como trascendental al scr, en un plano ético, el de la razón práctica, como «el Otro (Autrui)». Si la mera realidad de la cosa física siempre guarda una «exterioridad incognoscible» aún para la ciencia (realidad y cognoscibilidad nunca podrán identificarsc), mucho más la realidad del Otro: nunca, por definición, alguien (yo a aún nosotros como comunidad) puede pretender abarcar («comprender» verstehen) al Otro «dentro» de la «comprensión del ser», dentro de su mundo ${ }^{48}$. En el caso del Otro, la inefabilidad del individuo se reduplica por la inefabilidad de la libertad o incondicionalidad del otro mundo como historia ajena ${ }^{49}$. Es un límite absoluto

4. «Pues lo mismo es el pensar que el ser» (Parménides, Frag. 3: Diels, 1964, 1, p. 231).

4 Véase Dussel, 1977 , \$\$ 2.2.2-2.2.8; ed. alemana, pp. 36 y ss.

W Dussel, 1974.

4h En nuestra Filosofín de la Liberación $(\$ 2.2 .3 .1)$ distinguíamos entre «mundo" (Welt), en el sentido heideggeriano (y a él corresponde el ser, la ontología y la verdad del ser), y "cosmos" (Kosmos).

${ }^{*}$ La palabra «realidad» (Realität) deseo distinguirla claramente de otras tres denominaciones de Hegel, ya que no es ni el «ser (Sein)", ni la «existencia (Existenz)", ni la uefectividad (Wirklichkeit)" (véanse en la «Pequeña Lógica» de la Enciclopedia de Hegel, los $\$ \$ 86,123$ y 142). La «tealidad (Realität)" de la que hablo se encuentra más altá, es trascendental al «ser», "existencia (Existenz)" y "efectividad (Wirklichkeit)" hegelianas. Hemos hablado de esto en diversas obras nuestras. Pretendo que Marx tiene conciencia do cstas distinciones: puede haber plusvalor en un producto (ser), en una mercancía (existencia), pero no llegar a ser real (wirklich) -en el caso que no se venda la mercancia - y degradarse así el plusvalor en nada (aniquilación). Por su parte, el «trabajo vivo" es la "realidad real» más allá del capital (trascendentalidad de la realidad del sujeto del trabajo con respecto al ser del sistema, de la totalidad, del capital). Véase todo en mi obra Dussel, $1990 \mathrm{~b}$, cap. $9-10$.

4* De manera sugerente explica Marco Olivetti: $\alpha$ rra queste asimmetrie o diacronie (in termini temporali: la presenza di me sullaltro; la precedenza dell'altro su me) si dispiega e si piega la scena dell'essere, in una com-presenza delle due conscienze che in realtà non è mai sincronizzata o sintetizzata, se non uclla reppresentazione di un terzo osservatore, la cui capacita unificinte, tuttavia, è codizionata essa stessa dalla asimmetria-diacronia dell'uno e dell'altro della conscienza come uno e come altros (Olivetti, 1992, p. 132).

${ }^{311}$ Este tema lo toca con profundidad Vattimo en su obra sobre Schleiermacher (Vattimo, 1986, pp. 95 y ss.: "Coincidenza di linguaggio ed eticità). El camino to había abierto Schelling 
al lógos, a la «comprensión», al «ser» (como horizonte ontológico del mundo, de mi o nuestro mundo). El Otro cstá más allá (trascendentalidad) del ser —es la tesis de Levinas y de la Filosofía de la Liberación-. En este sentido más allá de la ontología, como trans-ontológico, se encuentra la ética (o la «meta-física» ${ }^{50}$ para Levinas) como experiencia racional del Otro como otro (re-conocimiento). Puedo desplegar cl horizonte de mi mundo y abarcar fragmentariamente aspectos pragmáticos del Otro; $\mathrm{el}$ Otro puede revelarse y hacerse comunicable, y por un mutuo aprendizaje podemos crear un ámbito comín inteligible. Pero el Otro como sujeto, como centro de «su» mundo, como historia propia, nunca podrá ser abarcado completamente por el logos. ¿Es la cuestión tradicional de la inefabilidad del individuo, de la inconmensurabilidad o de la incomunicabilidad? Es algo distinto; es la libertad del Otro como alteridad nunca manejable, nunca del todo comprensible, nunca del todo comunicable por el logos. Es la afirmación del límite absoluto de la razón: la razón del Otro, que, por supuesto, comprende su mundo y ejerce racionalmente en él su racionalidad. Pero negamos a la ontología el poder pretender ser el último momento posible ( $y$ también negamos al observador que coloca kmi [nuestro] mundo» y «tu [vuestro] mundo» ante sus ojos, y desde una posición de «tercero» los constituye a ambos inevitablemente desde su mundo de obscrvador; de esta manera la ontología sigue reinando, y cs lo que pretende Apel). Es necesario descubrir lo que hemos llamado la «razón ética originaria», que es la manera racional de relacionarse con la alteridad (con la Razón Dis-tinta del Otro, y no meramente Diferencia-en-la-Identidad). Desde y en «mi (nuestro) mundo* se revela kel Otro» como trascendente; en el mundo aparece un rostro (fenómeno) que indica el más allá del mundo: «el Otro». La experiencia práctico-ética del cara-a-cara, el respeto ante la libertad del Otro re-conocida como persona autónoma, no es el de una «comprensión» (primcramente) del ser, sino un «dejar-ser-al-Otro» en posición de espera ante su «revelación» ${ }^{51}$. Por todo ello no negamos la posibilidad del diálogo, de la comunicación racional simétrica, pero debemos mostrar siempre la imposibilidad de superar la exterioridad y las asimetrías-diacrónicas reales. No puede pretenderse «comprender» 0 «subsumir» completamente al Otro en el horizonte de mi (nuestro) mundo. El respeto, el re-conocimiento de su alteridad, exterioridad, es el «pour-Autrui» de la subjetividad humana ética. Sobre esto he escrito mucho y no debo repetirme ${ }^{52}$.

en sus conferencias de Berlín de 1841 sobre Philesophie der Offenbanung (vease Dussel, 1974, pp. 115 y ss.; Del Hegel definitivo al viejo Schelling $*$ ).

5) Esta cmeta-física», por supuesto, os postmetafísica (si por metafísica se entiende la posición ingenua de un realismo no crítico).

" «Revelación» del Otro, desde su libertad, no es mera «manifestación» del fenómeno; esto es lo que Schelling intentaba analizar como superación de Hegel en 1841 (Véasc Dussel, 1977 , \$2.4.74; Dussel, 1973, \& 35: « ¿Es Ja tematización dialéctica el límite del pensar?, II, pp. 146 y ss.).

:2 Véanse mis obras Dussel, 1973, 1974, 1977, etc. 
A este tema se aproximó como hemos visto, sin resolverlo, Horkheimer, cuando escribiendo acerca del «sentimiento de rebeldía, de compasión, de amor, de solidaridad», dice:

«La vida de la mayoría de la humanidad es tan miserable, las necesidades y humillaciones tan frecuentes, las cxpectativas sin éxito se dan en una relación tan inversamente proporcional que se entiende la esperanza de que este orden terrenal no sea el único ${ }^{53}$. Mientras el idealismo no explique esta esperanza como lo que es y trate de racionalizarla, lo que conseguirá es convertirse él mismo en medio para enmascarar su incapacidad de entender ese sentimiento» ${ }^{54}$.

Esta es la propuesta de una Ética de la Liberación, pero, a diferencia de Horkhcimer, al tener un sujeto histórico en torno al que articularse (el bloque social de los oprimidos o excluidos del capitalismo periférico, la gran mayoría do los habitantes del llamado antes Tercer Mundo), y al poder «racionalizar» esa esperanza (desde una «razón ćtica originaria», y desde un "pro-yecto de liberación»), se torna en un proyecto fillosófico al que el propio Horkheimer no pudo acceder. La Ética del Discurso retrotrajo esa problemática a la mera razón discursiva comunitaria simétrica-sincrónica, sin descubrir cl horizonte de la alteridad más allá de la dialéctica ncgativa. La comunicación simétrica-sincrónica es horizontal, tautológica —es la posición de Aristóteles, por ejemplo, que llamo "griega», y la de la Ética del Discurso-; la comunicación o la justicia como término de un proceso que parte desde la asimetria-diacrónica, se establece como una relación vertical -el Otro como macstro o como pobre, interpelante, descubierta ya on la posición bantú-egipcia, mesopotámica, semi$\mathrm{ta}^{55}$-: desde abajo hacia arriba. Esto es parte de una historia concreta de las «eticidades (Sittlichkeiten)", que condicionan también a la moral universal (que sigue estando articulada a una eticidad «convencional», de alguna manera e inevitablemente).

\section{Fundamentación ética de la praxis de liberación y fundamentación antiescéptica}

Acepto que si «el cscéptico no puede ser refutado, la argumentación válida sería imposible» ${ }^{56}$, y con ello la misma Ética de la Liberación. Pero hay diversos niveles de fundamentación, y ahora querría, en pocas palabras, comenzar a

$\$$ Contra Popper (véase F. Hinkelammert, 1984, cap. 5).

Horkheimer, 1970 , p. 76.

* En mi obra en elaboración Etica de la Liberación expongo este tema en cl cap. 1 . En el Lihno de los muertos, cap. 125, del Egipto, veinte siglos antes que los presocráticos, se habla ya dol criterio ético de aTuve hambre y me dieron de comer».

VEase Apel, 1995, \$\$ 2.7-2.8, pp. 119y ss. 
bosquejar una arquitectónica compleja de diversos principios, y por ello con diversos oponentes.

En efecto, la Ética del Discurso en su fundamentación debe oponerse al escéptico, mientras que la Ética de la Liberación acepta esta fundamentación (en su sentido que habrá que clarificar), aunque ticne un oponente previo, $y$, además, otros oponentes posteriormente.

La fundamentación de la validez intersubjetiva debe argumentar contra el escéptico y mostrar que se contradice en el acto mismo de argumentar contra la razón. Acepto. Lo que acontece es que esto tiene sentido en cl nivel moral de la validez intersubjetiva (donde la argumentación es una antigua institución que debe ser usada y defendida ${ }^{57}$ ), pero no sería ya válido en el nivel de una ética material, donde la reproducción y el crecimiento de la vida sería el principio universal -cuestión económica fundamental y en torno a lo cual se estructura la totalidad del pensamiento de Marx, Freud o Levinas-. En este caso, para fundamentar el principio de una ética material universal, habría que oponerse a aquel que justifica la posibilidad ética de la muerte (el límite absoluto de la no-reproducción de la vida). Y el que justifica tal posibilidad es el cínico - en sentido fuerte -.. Cuando un F. von Hayek, economista neoliberal, justifica que la compctencia del mercado tiende al equilibrio, y que la exclusión, pobreza o «los vencidos» de una tal competencia (que son hasta mayoría en la población de muchos países) es un efecto no intentado, está justificando dicha negación de la vida en muchas personas. Ante la pregunta de si la economía no debcría ocuparse del cumplimiento de las necesidades de los pobres, Hayck contesta que ésa sería función de la ética (para justificar algo así como la limosna). Esta justificación de la muerte de los vencidos es lo que denominaríamos «cinismo». En este caso, no es ya al escéptico-como el oponente de la moral universal que argumenta en favor de la validez intersubjetiva-, sino del cínico - como el oponente de una ética material universal $^{58}$ - al que hay que mostrar su inconsistencia (ya que el que el que justifica el que haya vencidos, el que justifica el suicidio, etc., con pretensión de racionalidad, to hace siempre en nombre de la vida, aunque sca de la de los sobreviventes de la competencia).

Pero, además, hay otros oponentes a los intentos de fundamentación, porque hay otros principios en la Ética de la Liberación. Al principio de factibilidad del acto se lc opone el utopista, el anarquista, que piensa poder efectuar el acto ético sin considerar las exigencias técnicas, económicas de escasez, etc., de la razón estratćgico-instrumental. Al principio propiamcnte crítico se le opondrá el conservador, que opina que el orden vigente es el mojor de los

Teniendo concitucia de que el escéptico siempre regresa de alguna manera, y el mismo Apel es escéptico, por ejemplo, de la ética material. Escepticismo los hay de muchas maneras; en este caso nos estamos oponicndo al escepticismo sadical que imposibilitaría usar la argumentación misma.

${ }^{s *}$ Este tema es objeto del capítulo 3 de la Efica de la Liberalización que estamos escribiendo. 
posibles, y habrá que demostrarle que se contradice igualmente; al principio crítico intersubjetivo de la validez antihegemónica, se le opondrá el dogmático (tanto en el poder dominador como entre las «vanguardias» izquierdistas); y, por último, al principio de liberación (de la factibilidad ética de las transformaciones posibles), se le opondrá cl antiutópico, que opina (como el Popper en alguna de sus obras) que las transformaciones (particularmente cuando son radicales) son imposibles, y que siempre causan males mayores. Si se acepta más de un principio, habrá diversos oponentes, y habrá que fundamcntar cada principio con diferentes argumentos. La Ética del Discurso sólo acepta un principio formal, uno solo, fundamentado el cual se ha fundamentado toda la ética. Si se aceptan diversos princípios, habrá que fundamentarlos con argumentos específicos y ante distintos oponentes. El escéptico radical es el oponente de la racionalidad discursivo-argumentativa, y la Ética de la Liberación está de acuerdo que hay que refutar dicho escepticismo - en el caso que se lo defina convenientemente-. Pero el escepticismo tiene sentido cuando se trata de la posición crítica de la misma razón contra el dogmátismo fundamentalista, como lo indica Levinas (y esto porque la misma Ética de la Liberación, cuando se opone crítica e intersubjetivamente desde los oprimidos a las ideologias de dominación, es también escéptica respecto de la razón dogmática).

El escéptico ni es el único ni el principal oponente de la Ética de la Liberación. Esta es la conclusión del descubrimiento de una arquitectónica mucho más complcja de principios que la Ética del Discurso ${ }^{59}$.

\section{BIBLIOGRAFÍA}

AMIN, Samir (1989): Eurocentrism, Monthly Review Press, New York.

APEL, Karl-Otto (1990): «Diskursethik als Verantwortungsethik», en Fornet-B., 1990, pp.10-40 («La Ética del Discurso como ética de la responsabilidad», en castellano Fornet-B., 1990, pp. 11-44).

- (1992): 1. «Die Diskursethik vor der Herausforderung der Philosophie der Befreing. Versuch einer Antwort an Enrique Dussels, en Fornet-B., 1992, pp. 16-54 (en castellano en Dussel, 1996).

- (1995): 2. «La ética del discurso ante el desufio de la filosofia latinoamericana de la liberacións, en Isegoria 1 (1995), pp. 108-125; y en Fornet-B., 1994.

Difi.S, Hermann (1964): Die Fragmente der Vorsokratiker, Weidmannsche Verlagsbuch., Zürich, t. I-III.

DUSSEL, Enrique (1969): El humanismo semita, EUDEBA, Buenos Aires.

"Este, y muchos otros, serán temas de la Ética de la Liberación que estoy escribiendo, ya que he comprendido que un debate mediante articulos breves es imposible. Es necesario exponer un discurso más comprensivo y por ello ya estoy avanzando dicha obra. 
- (1973): Para una ética de la liberación latinoamericana, Siglo XXI, Buenos Aires, t. I-II.

- (1974): Método para una Filosofía de la Liberación, Sígueme, Salamanca.

- (1975): El humanismo helénion, FUDEBA, Buenos Aires.

- (1977): Filosofía de la Liberación, Edicol, México (ed. inglesa Orbis Books, New York, 1985; ed. alcmana Argument, Hamburg, 1989).

- (1985): La producción teórica de Marx. Un comentario a los Gnundrisse, Siglo XXI. México.

- (1990a): «La Introducción de la Transformación de la filosofía de K.-O. Apel y la Filosofía de la Liberación», en castellano Fornet-B., 1990, pp. 45-104.

- (1990b): El último Marx (1863-1882) y la liberación latinoamericana. Un comentario a la tercera y a la cuarta redacción de El capital, Siglos XXI, México.

- (1991): «La razón del Otro. La interpelación como acto-de-habla», cn Antropos (Ca* racas), 199, enero-julio (1991), pp. 5-41 (aDie Vemunft des Anderen. Die Interpellation als Sprechakt , en Fornet-B., 1992, pp. 96-121).

- (1992a): «Del escéptico al cínico», en Signos (México), VI-III (1992), pp. 89-103 ("Vom Skeptiker zum Zyniker. Vom Gcgner der Diskursethik zu dem der Befreiungsphilosophie», en Fornet-B., 1993, pp. 55-65).

- (1992b): «Ermeneutica c Liberazione. Dalla Fenomenologia ermencutica ad una Filosofia della liberazione», en Filosofia e Liberazione. La sfida del pensiero del Terzo-Mondo, Capone Editore, Lecce (en castcllano en Dussel, 1994 c).

- (1993a): «Hacia un diálogo filosófico Norte-Sur (Algunos temas de discusión entre la Ética del Discurso y la Filosofía de la Liberación)», en Dussel, 1996 (en alemán: "Auf dem Weg zu cinem philosophischen Nord-Süd-Dialog", en Transzendental-pragmatik, A. Dorschel-M. Kettner et al. Hgb, Suhrkamp, Frankfurt, pp. 378-396).

- (1993b): 1492: El encubrimiento del Otro, Nueva Utopía, Madrid (Von der Erfindung Amerikas zur Entdeckung des Anderen, Patmos, Düsseldorf).

- (1993c): Las metáforas teológicas de Marx, El Verbo Divino, Estella.

- (1994a): «Respuesta inicial a K.-O. Apel y P. Ricoeur», en Dussel, 1996.

- (1994b): «Ética de la Liberación», en Fornet-B., 1994 (cd. Unisinos, pp. 145-170, de donde cito).

- (1996): Apet y Ricoeury la Filosofia de la Liberación, Editorial Anthropos, Barcelona (en inglés con otros trabajos sobre Taylor y Vattimo, en Humanities Press, New York, 1996).

Fornet-BeTAncourt, Raúl (1990): Hrsg, Ethik und Befreiung, Augustinus, Aachen (en castellano K.O. Apel-E. Dussel-R. Fomet, Fundamentación de la ética y filosofía de la liberación, Siglo XXI, México, 1992). I Seminario de Freiburg, 1989.

- (1992): Hrsg, Diskursethik oder Befreiungsethik?, Augustinus, Aachen (Debate en torto a la ética del discurso de Apel. Diálogo filosófico Norte-Sur, Siglo XXI, México, 1994). II Seminario de México, 1991.

- (1993): Hrsg., Die Diskursethik und ihre lateinamerikanische Kritik , Augustinus, Aachen. Ill Seminario de Mainz, 1992.

- (1994): Hrsg., Konvergenz oder Divergenz? Eine Bilanz des Gesprächs zwischen Diskursethik und Befreiungsethik, Augustinus, Aachen (publicado en portugués en Etica do Discurso e Filosofia da Libertaçâo. Modelos complementares, Antonio Sidekum, Hrsg, Unisinos, Sâo Leopoldo, 1994, de donde citamos). IV Seminario de Sâo Leopoldo. 
-.. (1995): Für Enrique Dussel. Aus Anlass seines 60. Geburstages, Augustinus, Aachen. HEGEL (1971): G.W.F.Hegel. Werke in zwanzig Bänden, Suhrkamp, Frankfurt, t. 1 (1971)-20 (1979).

HINKFI AMMERT, Franz (1984): Critica a la razón utópica, DEI, San José.

- (1994): «Diskursethik und Verantworlungs-Ethik: eine kritische Stellungnahmo", en Fornct-B., 1994 ( Ética del Discurso e ética de responsabilidad: uma tomada de posiçâo critica», ed.Unisinos, pp. 73-116, de donde cito).

- (1995): «Die Marxsche Wertlehre und dic Philosophie der Befreiung: einige Probleme der Diskursethik und der Marxismuskritik Apels», en Fornet-B., 1995, pp.35-74.

HORKHEIMER, Max (1970): "Materialismus und Metaphysik», en Traditionelle and kritische Theorie, Fischer, Frankfurt, pp.65-94.

HONNETH, Axel (1992): Kampf um Anerkennung. Zur moralischen Grammatik sozialer Konflikte, Suhrkamp, Frankfurt.

Lain Entralgo, Pedro (1961): Teoría y realidad del Otro, Revista de Occidente, Madrid, t. I-II.

LEVINAS, Emmanuel (1974): Autrement qu'être ou au-delà de l'éssence, Nijhoff, La Haye.

LUHMANN, Niklas (1984): Soziale Systeme, Suhrkamp, Frankfurt (ed. cast. Sistemas sociales, Editorial Alianza, Mćxico, 1991).

MATE, Reyes (1991): La razón de los vencidos, Anthropos, Barcelona.

MARX, Karl (1842): «Bemerkungen über die neueste preussische Zensurinstruktion», en $W E B$, t. 1 , pp. 3-27.

- (1857): Gnindrisse der Kritik der politischen Oekonomie, Dietz, Berlin, 1974.

- (1859): Zur Kritik der politischen Oekonomie, en $M E W$, t. 13, pp. 5 160.

- (1873): Das Kapital, en MEGA, Dietz, Berlin, 1987, t. 6.

- (1879): «Notas marginales al Tratado de Economia Política de Adolph Wagner», en $M E W$, t. 19 , pp. $355-383$.

Oliveti, Marco (1992): Analogia del Soggetto, Laterza, Roma.

PoppeR, Karl (1973): La miseria del Historicismo, Alianza, Madrid.

SCHNADELBACH, H., «Max Horkheimer und die Moralphilosophie des deutschen Idealismus», en Max Horkheimer heute: Werk und Wirkung, A. Schmidt-N. Altwickler, Hrsg., Frankfurt, pp. 52-79.

SchelkSHORn, Hans (1992): Ethik der Befreiung. Einfühning in die Philosophie Enrique Dussels, Horder, Freiburg.

Shanin, Teodor (1983): Late Marx and the Russian Road. Marx and the Peripheries of capitalism, Monthley Review Press, New York.

Sidekum, Antonio (1993): Ethik als Transzendenzerfahrung, Concordia Rcihc, Augustinus, Aachen.

- (1994): véase Fornct-B., 1994.

Theunissen, Michael (1965): Der Andere. Studien zur Sozialontologie der Gegenwart, Walter de Gruyter, Berlin.

ULRICH, Peter (1992): Transfomation der ökonomischen Vernunft. Fortschritsperspektiven der modemen Industriegesellschaft, Haupt, Bern.

Vatrimo, Giani (1986): Schleiermacher filosofo dell interpretazione, Mursia, Torino. 


\title{
T H E O R I A
}

\section{REVISTA DE TEORIA, HISTORIA Y FUNDAMENTOS DE LA CIENCIA}

\author{
FUNDADA EN 1952 - SEGUNDA EPOCA \\ FUNDADOR: Miguel SANCHEZ-MAZAS (†) \\ Revista asociada a la
}

Sociedad de Lógica, Metodología y Filosofía de la Ciencia en España

SUMARIO/CONTENTS DEL VOL. 11, N. 25

ENERO/JANUARY 1996

\author{
Javier ECHEVARRIA, $\quad 3-4 \quad$ Presentación Presentation \\ Andoni IBARRA (San Sebastian)
}

SECCION MONOGRAFICA: LA ARGUMENTACION: LOGICA Y RETORICA. PARTE IJ

(ARGUMENTATION: LOGIC AND RHETORIC. PART II)

Editor: José Miguel SAGÜLLO

$\begin{array}{rrl}\text { Carlos PEREDA (México D. F) } & 7-20 & \begin{array}{l}\text { Quées un buen argumeno? (What Is a Good } \\ \text { Argument? }\end{array} \\ \text { Eduardo de BUSTOS (Madrid) } & 21-40 & \begin{array}{l}\text { Metáforas polémicas: al caso de la argumentactón } \\ \text { (Polemic Metaphors: The Case of Argumentation) }\end{array} \\ \text { Rom HARRE (Oxford) } & 41-47 & \begin{array}{l}\text { Rhetoric and Realism } \\ \text { Eleonora MONTUSCHI (Oxford) }\end{array} \\ 49-61 & \text { Metaphor in Sacial Science }\end{array}$

\section{ARTICULOS/ARTICLES}

Alistair C. CROMBIE (Oxford) 65-76 Commimens and Styles of European Scientific Thinking

Victor SANCHEZ DE ZAVALA (San Sebastián) 77-141 Towards a less simple but sounder (psychological) Aurelio PEREZ FUSTEGUERAS (Granada)

143-159 Sobre sémántica de los términos de género natural (On the Semantics of Natural-kind Words)

Julian MARRADFS (Valencia) 161-183 Sobre las condiciones de la comprenstón transcultwral (On the Conditions of Transcultural Understanding)

Manuel PEREZ OTERO (Barcelona) 185-201 Verdadnecefaria versus teorema de lógica modal

Ton SALES (Barcelona) 203.228 Logic of Assertions

RECENSIONES Y LIBKOS RECIBIDOS/BOOK REVIEWS AND BOOKS RECETVED

CRONICAS Y PROXIMAS REUNIONESINOTICES AND ANNOUNCEMENTS

\section{REDACCION/EDITORIAL OFFICE/REDACTION}

ESPANAJSPAIN: CALIJ-THEORIA, Alcalde Jose Elosegui, 275, E 20015, apartado 1.594, 20080, San Sebastián, España. Tel: (34 43) 2917 25. Fax (A. Ibarra): (34 43) 31 10 56. E-mail: theoria (Osf.eluu.es.

EXTRANIERO/FOREIGN COUNTRIES: Asociación Cultural España-THEORIA, Case 2.730, 1211 Gèneve-2, Suisse.

\section{DISTRIBUCION/DISTRIRUTION}

Para suscripciones, números atrasados y cambios de dirección: For subscriptions, back volumes and changes of address: Servicio Editorial, Unjersidad del Pais Vasco, apartado 1.397, E. 48080 Leioa, España. Tel.: (34 4) 4647700 (ext. 2153$)$. Eax: (34 4) 4801314. 